\title{
An Intervention-Based Active Learning Strategy Employing Principles of Cognitive Psychology
}

\author{
Gaganpreet Sidhu ${ }^{1}$ and Seshasai Srinivasan ${ }^{2}$ \\ McMaster University \\ Corresponding Authors: ${ }^{1}$ sidhug1 @ univmail.cis.mcmaster.ca, ${ }^{2}$ ssriniv@ $@$ mcmaster.ca
}

\begin{abstract}
The objective of this research is to investigate an intervention-based active learning strategy incorporating the principles of cognitive psychology to enhance student learning in an undergraduate engineering mathematics course. In this strategy, the classroom was completely flipped, i.e., the students were assigned weekly reading assignments and had to take a quiz before joining the classroom. Inside the classroom, the lectures were replaced with group-problem solving sessions. Specifically, students were divided into small groups where they collectively solved worksheets containing several problems. By design, the worksheets integrated the key principles of cognitive science in learning that are conducive to long term retention of the topics, namely, reinforcement, spacing and instant feedback. Subsequently, the students were given takehome practice problem sets to master the concepts. On comparing the student learning outcomes from this strategy with the outcomes from the traditional lecturing approach, it was found that the students indulging in the carefully designed active learning environment performed better. It can be concluded that the improved student learning and retention can be attributed to the combination of active learning and the effective intervention strategy employed in the course.
\end{abstract}

Keywords: Cognitive psychology, active learning, flippedclassroom.

\section{INTRODUCTION}

In an effort to improve the quality of education, an immense amount of attention has been paid on effective teaching and learning, and long term retention of the concepts taught to the students. It is recognized that in a traditional lecturing approach the students are able to master only about $20 \%$ of the course's concepts [1] that are delivered. To overcome this limitation, several investigations have focused on identifying the optimal approach to deliver lectures and enhance student learning.
Numerous researchers have shown that active and cooperative learning can significantly improve student learning, example [2-4]. Some investigations have advocated the use of computer-based active instruction to enhance student learning [5, 6]. However, these approaches can either be too expensive [6] and/or place an enormous amount of work load on the instructors [7].

More recently, studies have used the principles of cognitive science to deliver lectures and have found success in improving student learning and retention $[4,8$, $9,10]$. In this work, we integrate the principles of cognitive science into a flipped-classroom mode of teaching, and study their effect on student learning and long-term retention in an undergraduate course in mathematics for engineering students.

The specific details of the study including the course, materials, data collection and analysis procedures, are described in the Sec. II. The results found from the analysis of the data are discussed in Sec. III and pertinent conclusions are drawn in Sec. IV.

\section{METHODS}

The study was conducted in an undergraduate course on Differential Calculus taught over a period of one term. 111 students in the first section (control section) were taught the course using the standard lecture format. 106 students in the second section (experimental section) received the Intervention-based Active Learning (iAL) instruction. The specifics of the course design, the contents of the course and the evaluation process are discussed in the ensuing subsections.

\subsection{Course Design}

Student performance in the course in both sections was evaluated using four term tests and a final exam. The terms tests were administered immediately after the predetermined set of topics for the respective tests were taught in the class.

In the control section, the students were taught using the standard lecturing approach. On the other hand, the 
students in the experimental section were taught using the iAL strategy. In this, the students were assigned weekly reading assignments and had to take a quiz before joining the classroom. Inside the classroom, following a brief introduction to the concepts (about $10-15 \%$ of class time), the students participated in group problem solving sessions. Specifically, the students were divided into small groups where they collectively solved worksheets containing several problems.

A key aspect of the iAL approach is the problem solving sessions. By design, the worksheets in these sessions integrated the three key principles of cognitive science, namely, Reinforcement, Spacing and Feedback. The motivation behind the integration of these principles in the intervention strategy is their positive effect on learning and long-term retention of the material, which are as follows: (a) Reinforcement: By repeatedly recalling the concepts from the memory, the information is more permanently stored in the memory. (b) Spacing: To aid the retention of the material for a longer duration of time, the material must be practiced over a longer span of time. (c) Instant Feedback: An immediate corrective feedback can help in better understanding of the material more effectively.

\subsection{Materials}

The students in both sections were taught the same material. While the control section was tested on the material over two term tests, the experimental section was tested on the same concepts over 4 term tests. The topics that the students were tested can be categorized into (i) preparatory material and (ii) differential calculus. The preparatory material covered topics such as: solving linear and quadratic equations and inequalities, functions, domain and range, conics, trigonometric functions and equations, exponential and logarithmic equations, matrices and arrays, determinants, Cramer's rule, vector dot and cross products. The differential calculus part of the course covered topics including: limits, continuity, derivatives and rates of change, various rules of differentiation, higher order differentials, and applications of differential calculus (related rates, and optimization).

For the control section, Test 1 covered the preparatory material and Test 2 covered the differential calculus. On the other hand, for the experimental section, the preparatory material was covered in Tests 1 and 2, whereas the differential calculus was covered in Tests 3 and 4.

Each test was for a duration of one hour. All the tests were equally weighted towards the final grade of the student. The first two tests had around 6 questions each whereas 3 rd and the 4 th test had 4 questions each. The final exam was comprehensive and was for a duration of 3 hours.

\subsection{Procedure}

For the students in the control section, all the topics were taught by first explaining the concepts and subsequently solving a few examples on the white board during the in-class instruction period. At the end of each topic, the students were provided with problem sets for practice outside the classroom. The students were encouraged to seek assistance if needed either during posted office ours or by making appointments.

For the students in the experimental section, lecture notes were provided to the students before they came to the class. They were expected to read the material and take a preliminary quiz before the came to class. Inside the class, the students were divided into groups of 3-5 students and they collectively solved the problems. The problems were drawn from the same pool of practice problem sets that were assigned to the students in the control section.

In a bid to integrate the principles of cognitive science, described in the introduction section, the worksheets were designed such that some of the questions were from earlier topics. The students were expected to recall the concepts and thereby reinforce them when they do it in class again. Additionally, the solutions to the questions were immediately verified and corrective feedback was provided to the students immediately. To assist with this process, a qualified teaching assistant was also present in the class to make the process efficient and accomplish this in a time bound manner. Specifically, the objective was to ensure that every student in the class had all their solutions evaluated and had a corrective feedback to improve their understanding of the topics. Put differently, the problem solving sessions in the class ensured that by the end of the class, every student in the class had arrived at the correct solution and had a good understanding of the solution methodology.

\section{RESULTS AND DISCUSSION}

\subsection{Course Components}

The performance of the students in the two major components of the course are summarized in Table 1 and the average scores are also shown in Fig. 1 
Table 1: Performance of the students in the two sections

\begin{tabular}{|c|c|c|c|c|}
\hline & $\begin{array}{c}\text { Control } \\
\text { Section }\end{array}$ & $\begin{array}{c}\text { Exp. } \\
\text { Section }\end{array}$ & $\begin{array}{c}\% \\
\text { Change }\end{array}$ & $\begin{array}{c}\text { Letter } \\
\text { Grade } \\
\text { Change }\end{array}$ \\
\hline $\begin{array}{c}\text { Preparatory } \\
\text { Material }\end{array}$ & 82.5 & 86.8 & 5 & 0.33 \\
\hline $\begin{array}{c}\text { Differential } \\
\text { Calculus }\end{array}$ & 58.1 & 65.7 & 13 & 0.67 \\
\hline Final Exam & 43.5 & 65.7 & 51 & $>2$ \\
\hline $\begin{array}{c}\text { Course } \\
\text { Grade }\end{array}$ & 53.5 & 76.2 & 42 & $>2$ \\
\hline
\end{tabular}

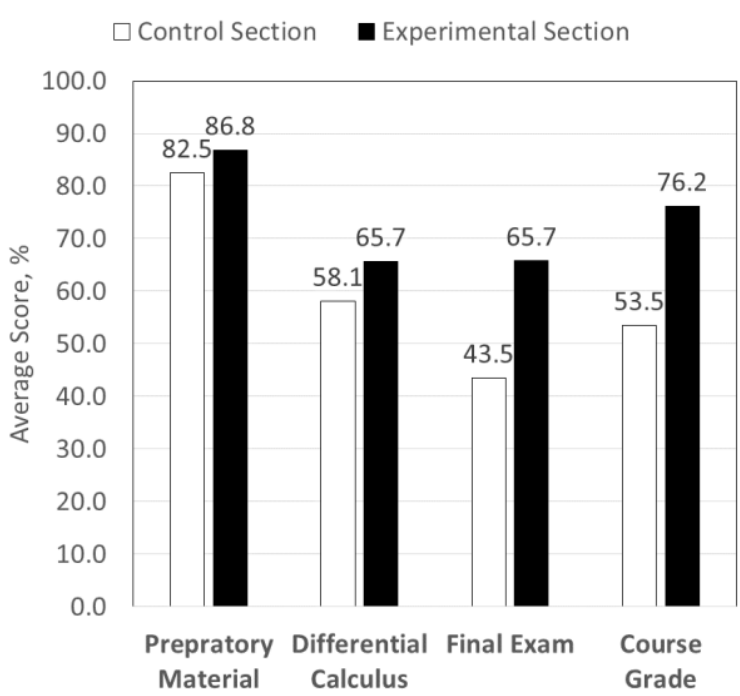

Fig. 1. Average score in the two components of the course, the final exam and the course grade.

As seen in Fig. 1, in both sections, there is a sharp fall in the performance of the student from the first component of the course, i.e., preparatory material, and second component of the course, namely, the differential calculus. This is expected because all the students are expected to have a background knowledge covered in the preparatory material. As a result, the initial weeks of the course primarily serves as a review of this material.

On the other hand, the topics covered in the differential calculus component of the course is new material and is not as easily mastered. Unlike the topics in the first component, the students have not had a chance to practice this for several terms. In other words, they have been tested within three weeks of learning this material for the first time.

On comparing the performance of the students between the two sections, it is seen that the performance of the experimental section is marginally better $(5 \%)$ in the preparatory material. Given the variation of the sample population, it can be argued that this is change is perhaps insignificant to attribute it to the anticipated positive effects of the iAL approach of teaching.

A much noticeable change is obtained in the second component of the course where new material is introduced to the students. As summarized in Table 1, the average score of the student is about $58 \%$ whereas a student in the experimental section has an average score of about $66 \%$. This is about $13 \%$ higher performance of the students who are taught using the iAL approach. In other words, the use of integrated Active Learning resulted in about two-third of a letter grade change.

\subsection{Final Exam and Course Grade}

The final exam was comprehensive and had about 13 questions for both sections. Some of the questions had multiple parts. The performance of the students in the final exam and the overall course grade are also summarized in Table 1 and shown in Fig. 1

A comparison between the two sections indicate that the students in the experimental section performed over $20 \%$ better than the students in the control section. This is over $50 \%$ improvement from the control section or more than 2 letter grades higher than the control section. Similarly, the final course grade of the students improved over 2 letter grades from D to B.

A closer look at Fig. 1 shows that the performance of the students in the control section decreased continuously from the preparatory material to the final exam. The continuous fall indicates that the students are not able to retain the material. On the other hand, in the experimental section, from an initial fall from about $87 \%$ to $66 \%$ the performance of the student remains the same during the final exam. This is indicating that an introduction of new material takes a bit longer to adjust. However, most of the introduced material is retained well through the term.

\section{SUMMARY AND CONCLUSIONS}

In this study, the effects of integrating the principles of cognitive science principles with an active learning methodology on the performance of the students are explored. Specifically, a quantitative investigation was made in which a $1^{\text {st }}$ year undergraduate course in the area of differential calculus taught for engineering students using either (a) the traditional approach, or (b) an Intervention-based Active Learning (iAL).

The first approach involved the use of the classical method of teaching in which following a regular classroom instruction on the concepts, practice problem sets were assigned for the students to master the topics outside the classroom. In the iAL approach, the classroom was completely flipped. Specifically, all the lecture notes were made available to the students prior to the class. The 
students had to read the material and appear for an online quiz. The quiz was integrated into the course only to force the students to participate in the outside-the-class reading. In the classroom, following a brief lecture for about 10 $15 \%$ of the class time to elucidate the topics, the students were split into groups of 3-5. The groups were assigned worksheets containing problems from the same practice problem sets that were assigned to the students instructed in the traditional approach.

It was found that the students in both sections did well in the first component of the course, namely, the preparatory material. The topics in this material, listed in Sec. 2.2, were a review of the pre-requisite concepts. Since the students have been working on these concepts for nearly two years through their high school, these topics have been reinforced. As a natural consequence, irrespective of the mode of instruction, the students perform well in recalling these concepts.

On the other hand, the new concepts taught in the differential calculus component of the course was better received by the students in the experimental section of the course, who received the iAL instruction. This is reflected in the better performance of the students from the experimental section (c.f. Table 1).

Through a continuous recalling and reinforcements of the concepts through the worksheets, the students in the experimental section were able to retain $20 \%$ more material during the final exam. Eventually, the overall performance of the students in the experimental section was more than 2 letter grades higher.

\section{References}

[1] K. E. Wage, J. R. Buck, C. H. Wright and T. B. Welch, "The Signals and Systems Concept Inventory," IEEE Transactions on Education vol. 30, pp. 448-461, 2005.

[2] M. Prince, "Does Active Learning Work? A Review of the Research", Journal of Engineering Education, vol. 93, pp 223-231, 2004.

[3] C. H. Crouch and E. Mazur,"Peer Instruction: Ten Years of Experience and Results", Americal Journal of Physics, vol. 69, pp 970-977, 2001.

[4] G. Sidhu and S. Srinivasan, "Technology and Intervention Based Instruction for Improved Student Learning", in Proc. International Conference on Engineering Education and Research, ICEER2014, paper number Mo6_5, 2014.

[5] E. F. Redish, J. M. Paul and R. N. Steingberg, "On the effectiveness of Active-Engagement Microcomputer-Based Laboratories", Americal Journal of Physics, vol. 65, pp. 45-54, 1997.

[6] T. Murray, "Authoring Intelligent Tutoring Systems: An Analysis of the State of the art", International Journal of Artificial Intelligence in Education, vol. 10, pp. 98-129, 1999.

[7] P. A. Kirshner, J. Sweller and R. E. Clark, "Why Minimal Guidance During Instruction Does not Work: An Analysis of the Failure of the Constructivist, Doscovery, ProblemBased, Experiential and Inquiry-Based Teaching", Educational Psychologist, vol. 41, pp. 75-86, 2006.
[8] L. Deslauriers, E. Schelew and C. Wieman, "Improving Learning in a Lerge-Enrollment Physics Class", Science, vol. 332, pp.862-864, 2011.

[9] A. C. Butler, E. J. Marsh, Jp. P. Slavinsky and R, G, Baraniuk, "Integrating Cognitive Science and Technology Improves Learning in a STEM Classroom”, Educ. Psychol. Rev., DOI 10.1007/s10648-014-9256-4.

[10] S. Srinivasan and D. Centea, "Applicability of Principles of Cognitive Science in Active Learning Pedagogies", in International Joint Conference on the Learner in Engineering Education (IJCLEE 2015), to appear, 2015. 